\title{
Horseshoe kidney with growth retardation: Don't forget Turner syndrome
}

\author{
Seçil Arslansoyu-Çamlar ${ }^{1}$, Alper Soylu¹, Ayhan Abacı², Mehmet Atilla Türkmen¹, \\ Ayfer Ülgenalp ${ }^{3}$, Salih Kavukçu ${ }^{1}$ \\ Division of ${ }^{1}$ Pediatric Nephrology, and ${ }^{2}$ Pediatric Endocrinology, Department of Pediatrics, ${ }^{3}$ Department of Medical Genetics, \\ Dokuz Eylul University, Faculty of Medicine, Izmir, Turkey.E-mail: secilars@yahoo.com, secil.camlar@deu.edu.tr \\ Received: 11 May 2015, Revised: 3 June 2015, Accepted: 13 July 2015
}

\begin{abstract}
SUMMARY: Arslansoyu-Çamlar S, Soylu A, Abacı A, Türkmen MA, Ülgenalp A, Kavukçu S. Horseshoe kidney with growth retardation: Don't forget Turner syndrome. Turk J Pediatr 2016; 58: 227-229.

Horseshoe kidney is the most frequent renal fusion anomaly that is usually asymptomatic and isolated malformation. However it can be seen with various syndromes and chromosomal anomalies. It was reported that $15-35 \%$ of Turner syndrome cases (TS) also display horseshoe kidney condition. TS is a chromosomal anomaly that had been characterized by delayed puberty, short body height and gonadal dysgenesis. In this report a five-year-old girl with horseshoe kidney, which has growth retardation during follow-up as only symptom of Turner syndrome.
\end{abstract}

Key words: horseshoe kidney, growth retardation, Turner syndrome.

Horseshoe kidney is the most frequent renal fusion anomaly with a rate of $1 / 500$ healthy births ${ }^{1}$. It is usually asymptomatic and an isolated malformation. However it can be seen with various syndromes and chromosomal anomalies. It was reported that $15-35 \%$ of Turner syndrome cases (TS) also display horseshoe kidney condition ${ }^{2,3}$. TS is a chromosomal anomaly that had been characterized by delayed puberty, short body height and gonadal digenesis. Its rate of occurrence is $1 / 2500^{4}$.

Herein we report a five-year-old girl with growth retardation and horse shoe kidney as the only symptoms of Turner sydrome.

\section{Case Report}

A ten-month-old girl was administered for recurrent urinary tract infection. She was born $3050 \mathrm{~g}$ by cesarean delivery. Her parents were not consanguineous. Physical examination revealed a body weight of $8.3 \mathrm{~kg}(25-50 \mathrm{p})$, a height of $69 \mathrm{~cm}(25-50 \mathrm{p})$ and a blood pressure of $90 / 40 \mathrm{mmHg}$. Other systems' assessment did not show any pathology or a dysmorphic anomaly. Laboratory examination revealed normal whole blood count, serum biochemistry and urine analysis. Urinary ultrasound was reported as normal. The voiding cystourethrography did not reveal any vesicourethral reflux. DMSA-Tc $99 \mathrm{~m}$ scintigraphy revealed a $35 \%$ right and $65 \%$ left orientation with closer kidneys near inferior poles. As lower urinary tract infections continued another ultrasonography was done when the patient was two years old. This ultrasonography showed a right kidney of $64 \mathrm{~mm}$, left kidney of $74 \mathrm{~mm}$ and an additional hypoechoic isthmus of $6 \mathrm{~mm}$ in diameter within the region on the right side.

When she was 3 years old, physical examination revealed a body weight of 11.6 $\mathrm{kg}(3-10 \mathrm{p})$, a height of $88 \mathrm{~cm}(3-10 \mathrm{p})$ and a blood pressure of $90 / 40 \mathrm{mmHg}$. Clinical follow-up reported percentile loss (from 1025 to 3-10 p interval) in anthropometric parameters (body weight and height). Her growth chart was demonstrated in Fig. 1. The anti-gliadin IgG for celiac disease was found negative. The reduction in growth rate together with the horseshoe kidney condition led us towards a TS diagnosis. Karyotype analysis, hence, showed 46, X, i (X) (q10). Repeated abdominopelvic ultrasonography showed a $60 \mathrm{~mm}$ right kidney, a $72 \mathrm{~mm}$ left kidney, the bilateral parenchyma thickness of $8 \mathrm{~mm}$ 
and a $6 \mathrm{~mm}$ hypoechoic isthmus during iliac bifurcation stage. Uterus and ovarian tissues were not displayed. Echocardiography was normal. The patient, with a body height of 94 $\mathrm{cm}(<3 \mathrm{p}$, SDS -2.35$)$, had an annual growth rate of $3.3 \mathrm{~cm}$ (maternal height is $165 \mathrm{~cm}$, while paternal height is $170 \mathrm{~cm}$ ). L-Dopa peak value on 90th minute was $3.57 \mathrm{ng} / \mathrm{nl}$, IGFBP-3 was $4.83 \mathrm{ng} / \mathrm{nl}$. The patient started a growth hormone treatment when she was 54 months old, developing its annual growth rate to $7 \mathrm{~cm}$ during 15 months of growth hormone treatment.

\section{Discussion}

The parenchymal isthmus that occurs in horseshoe kidney is thought to develop as a result of nephrogenic cell migration during the fifth gestational week of embryogenesis. The kidneys fuse in a location very close to the emerging point of inferior mesenteric artery (anterior aorta) through a mediocre isthmus. The fusion locates itself into the pelvis, or within the inferior lumbar region as anti-gravitational growth is obstructed ${ }^{1}$.

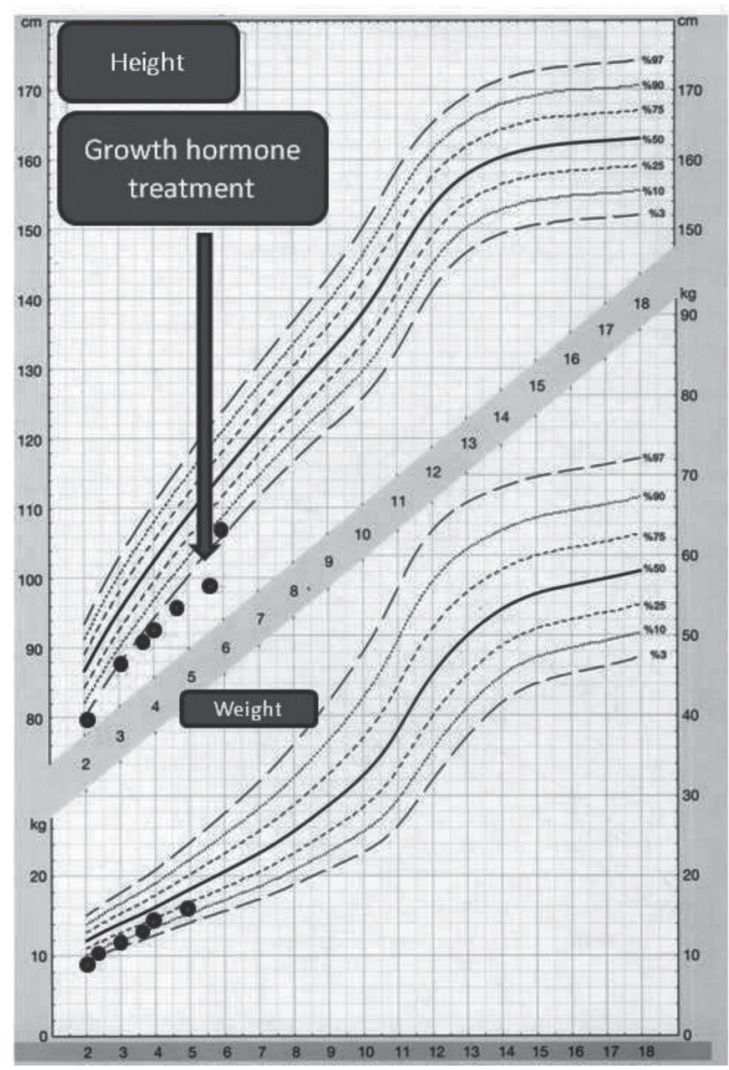

Fig. 1. Weight and height chart of the patient.
Ectopy is characterized by malrotation and vascular changes ${ }^{1}$. Ultrasound assessment can easily hint at it via the presence of an isthmus. In younger children, though, the diagnosis of horseshoe kidney is not easy. Nuclear imaging techniques can be used in the evaluation of localization and function of kidneys. In our case there had been no incident of isthmus during the first time in ultrasound. As it is always an isolated anomaly, cases can be diagnosed following recurrent urinary tract infections, hydronephrosis, obstructive uropathy (mostly ureteropelvic junction obtruction) and nephrolithiasis 5,6 . Congenital anomalies can also occur ( $4 \%$ hypospadias, $4 \%$ unaligned testicles, $7 \%$ bicornate uterus, $7 \%$ septated vagina, $10 \%$ urethral duplication, $20 \%$ urethropelvic compound obstruction, $50 \%$ vesicourethral reflux, $1 \%$ multicystic dysplasia and $50 \%$ nephrolithiasis) ${ }^{7}$.

Horseshoe kidney sometimes is a component of various syndromes and chromosomal anomalies. The following conditions can be reported amongst such: Acrofacial disostosis syndrome, diabetic maternal child, Antley-Bixler syndrome, fetal alcohol syndrome, Fanconi's anemia, focal dermal hypoplasia, BowenConradi syndrome, caudal regression syndrome, Juber-Hayberg syndrome, Kabuki, Pallister-Hall syndrome, pylorus stenosis, Robert's syndrome, thalidomide embryopathy, trisomy 13, 18, 21, 22 and VATER anomaly.

Typical clinical indicators of TS are morphologic malformations like short body height, mane neck, lowered hair peripherum, heightened arteries, malformed ears, split nipples, cubitus valgus and hyperconvex nails ${ }^{4}$. However, these stigmata are not observed in every single case. Mane neck and lymphedema in the hands and feet are observed during the infantile period. Short body height and delayed puberty onset during the prepubertal stages are indicators of a possible TS conditions and a karyotype analysis is highly recommended. Cases without typical stigmata are screened for TS in later stages and hence are diagnosed later. With respect to the comorbid system anomalies, a periodic screening during diagnosis and follow up for TS is recommended ${ }^{8}$. Urinary system assessment is especially underlined as $30-40 \%$ of cases show comorbidity with urinary track malformations as collecting system malformations (55\%) and 
kidney rotation anomalies (16\%), even though no symptom might be discernible during diagnosis $^{2,8}$. In our case the TS diagnosis was put after the horseshoe kidney and clinical follow up of limited body growth. Fiftyfive percent of patients with TS syndrome show a 45, XO karyotype. Malformation rates comorbid with monosomic and mosaic karyotype conditions show variations. Bilge et al. ${ }^{2}$ assessed 82 patients with TS for urinary system malformations and reported a higher rate of occurrence of 45, XO karyotype for renal malformations. In this case study a similar assessment had been considered as a risk factor for renal malformation.

\section{Conclusion}

This case study outlines the importance of close follow up for growth rate analysis in patients with kidney anomaly and highlights the necessity of considering TS as the distinguishing diagnosis for cases with slow growth rate.

\section{REFERENCES}

1. Natsis K, Piagkou M, Skotsimara A, Protogerou V, Tsitouridis I, Skandalakis P. Horseshoe kidney: a review of anatomy and pathology. Surg Radiol Anat 2014; 36: 517-526.

2. Bilge I, Kayserili H, Emre S, et al. Frequency of renal malformations in Turner syndrome: analysis of 82 Turkish children. Pediatr Nephrol 2000; 14: 1111-1114.

3. Kleta R, Brämswig JH. Horseshoe kidney and Turner syndrome. Nephrol Dial Transplant 2000; 15: 1094.

4. Morgan T. Turner syndrome: diagnosis and management. Am Fam Physician 2007; 76: 405-410.

5. Obermayr F, Szavay P, Schäfer J, Fuchs J. Ureteropelvic junction obstruction and calyceal diverticulum in a child with Turner syndrome and horseshoe kidney. J Pediatr Urol 2010; 6: 463.e1-4.

6. Rodriguez MM. Congenital Anomalies of the Kidney and the Urinary Tract (CAKUT). Fetal Pediatr Pathol 2014; 33: 293-320.

7. O’Brien J, Buckley O, Doody O, Ward E, Persaud T, Torreggiani W. Imaging of horseshoe kidneys and their complications. J Med Imaging Radiat Oncol 2008; 52: 216-226.

8. Bondy CA, for the Turner Syndrome Consensus Study Group. Care of girls and women with Turner Syndrome: a guideline of the Turner Syndrome Study Group. J Clin Endocrinol Metab 2007; 92: 10-25. 